\title{
Clinical and epidemiological characteristics of pyogenic liver abscess in people 65 years or older versus people under 65: a retrospective study
}

Jorge Peris ${ }^{1,2}$, Pablo Bellot ${ }^{3}$, Pablo Roig ${ }^{1,2}$, Sergio Reus ${ }^{2,4}$, Sara Carrascosa ${ }^{5}$, Gregorio González-Alcaide ${ }^{6}$, José M. Palazón ${ }^{2,3}$ and José M. Ramos ${ }^{2,7^{*}}$

\begin{abstract}
Background: To analyse the clinical, epidemiological, microbiological and prognostic differences of pyogenic liver abscess (PLA) in older ( $\geq 65$ years of age) versus younger patients ( $<65$ years).

Methods: Multicentre, retrospective cohort study in all patients with PLA admitted to two Spanish hospitals from January 2000 to January 2014. Cases were divided into two age groups ( $<65$ years and $\geq 65$ years) for comparison of clinical, epidemiological and microbiological characteristics as well as treatment.

Results: Of 98 patients analysed, 40 patients were younger than 65, and 58 were aged 65 or older. Significant associations in the older group were found with female sex (adjusted odds ratio [ORa] 9.0; 95\% Cl 1.4, 56), non-cryptogenic origin (ORa 14.5; 95\% Cl 1.6, 129), absence of chronic liver disease (ORa 14; 95\% Cl 1.3, 155), Escherichia coli infection (ORa 7.7; 95\% Cl 1.03, 58), and incidence of complications (ORa 2.3; 95\% Cl 1.04, 5.4). Mortality was 8.2\% overall, although all deaths occurred in the older group $(8 / 58 ; 13.8 \%)(p=0.02)$.
\end{abstract}

Discussion: Our results are in consonance with other published studies. Older patients with PLA tend to present more anomalies in the biliary tract (Kai et. al, World J Gastroenterol 18: 2948-295, 2012, Rahimian et. al, Clin Infect Dis 39:1654-9, 2004, Seeto, Medicine (Baltimore) 75:99-113, 1996, Kao et.al, Aliment Pharmacol Ther 36:467-76, 2012, Lai et. al, Gastroenterology 146:129-37, 2014), while younger patients are more often male and present more commonly with previous liver disease (especially related to alcohol) and cryptogenic PLA.

Conclusion: In patients aged 65 or older, PLA was more common in women and in those with a history of biliary disease, and E. coli was the most frequent bacterium. Mortality was also higher in the older group.

Keywords: Liver abscess, Pyogenic, Epidemiology, Microbiology, Mortality, Aged, Female, Escherichia coli

\section{Background}

Pyogenic liver abscess (PLA) is defined as a collection of pus surrounded by a fibrous layer of tissue in the liver. Reported incidence in the literature ranges from 2 to 86 cases per 100,000 hospital admittances/year [1-4]. However, PLA has doubled in incidence in the most recent

\footnotetext{
* Correspondence: jramosrincon@yahoo.es

²Department of Clinical Medicine, Universidad Miguel Hernández de Elche, Campus of Sant Joan d'Alacant, Sant Joan d'Alacant, Alicante, Spain

${ }^{7}$ Department of Internal Medicine, Hospital General Universitario de Alicante

Alicante, Alicante, Alicante, Spain

Full list of author information is available at the end of the article
}

decades for several reasons: immunosuppressive treatments in cancer patients and/or transplant recipients, the use of invasive techniques to manage hepatobiliary disease, and greater diagnostic efficacy through imaging techniques [5, 6]. Moreover, some studies point to a possible relationship with colon cancer [7].

Modern diagnostic techniques allow more exact positioning of the PLA, which has facilitated the development of therapeutic techniques such as drainage or aspiration. PLA is associated with high morbidity and mortality; however, these have decreased thanks to early detection and the development of different treatments, 
ranging from antibiotics to image-guided drainage/aspiration procedures. Despite these advances, studies still estimate a mortality rate of 2 to $31 \%[3,4,8,9]$.

The microorganisms most commonly responsible for PLA are Klebsiella pneumoniae followed by Escherichia coli. In addition, diverse series have described the recent appearance of rarer multi-resistant germs such as $K$. pneumoniae or E. coli producers of beta-lactamases or multi-drug resistant Pseudomonas aeruginosa [10].

Advanced age is an increasingly important factor for both the prognosis and the severity of numerous pathologies, but few studies describe the clinical features in the elderly compared to younger patients $[11,12]$. Thus, this study was conceived to fill that gap in knowledge; it aims to analyse the clinical, epidemiological, microbiological and prognostic differences of PLAs in older ( $\geq 65$ years of age) versus younger patients ( $<65$ years).

\section{Methods}

Multicentre, retrospective cohort study in all patients with liver abscess admitted to the Hospital de San Juan de Alicante and to the General Hospital of Alicante from January 2000 to January 2014. Among these patients, we performed a systematic search of hospital records in order to select consecutive cases with an abscess corresponding to the International Classification of Diseases (ICD) code ICD-9-CM 572.0. PLA was defined as any abscess found within the liver parenchyma that was of bacterial origin. According to criteria published by Alvarez and colleagues [12], diagnosis was based on clinical features, evidence from imaging studies (e.g. single or multiple space-occupying lesions on liver ultrasonography or abdominal computerised tomography [CT]), blood culture, pus from liver aspirates, surgical findings, and resolution of the lesion(s) after antibacterial chemotherapy. We excluded patients from analysis for the following reasons: fungal abscess, parasitic abscess and amoebic abscess.

We collected data for demographic variables: age and sex; risk factors: previous chronic liver disease, organ transplant, human immunodeficiency virus, inflammatory intestinal disease (including primary sclerosing colangitis), cancer; clinical manifestations: abdominal pain, fever and jaundice; laboratory parameters: haemoglobin, total leukocytes, total bilirubin, alkaline phosphatase, gamma glutamil transferase (GGT), C-reactive protein (CRP); radiological techniques used for diagnosis: ultrasound, abdominal CT scan, magnetic resonance imaging (MRI); origin and aetiology of PLA; microbiological results (from samples of the PLA itself and, when available, blood cultures); and health care indicators: treatment (antibiotic alone, antibiotic plus percutaneous aspiration, and antibiotic plus surgical drainage with or without percutaneous aspiration), length of treatment, antibiotic used, complications, length of hospital stay, and mortality.

We classified PLAs as being small $(<4 \mathrm{~cm}$, with no need for drainage), large $(4 \mathrm{~cm}$ to $<10 \mathrm{~cm})$, or giant $(\geq 10 \mathrm{~cm})$ $(13,14)$. Chronic liver disease was defined as progressive destruction of the liver parenchyma over a period greater than 6 months leading to fibrosis and cirrhosis, including primary biliary cirrhosis (PBC), primary sclerosing cholangitis, autoimmune hepatitis, drug-induced liver disease or viral chronic hepatitis. The aetiological origin of PLA included: cryptogenic (treating physician could not identify the source of infection despite appropriate investigation), biliary (in patients with gallstones and a clinical picture of cholecystitis/cholangitis), contiguous (in patients with intra-abdominal abscess), portal (in case of a documented abdominal infection such as appendicitis or diverticulitis), arterial (with a documented bacteraemic episode and no history of other intra-abdominal infections) and traumatic (where the abscess was secondary to a previous abdominal surgical intervention) [13].

Cases were divided into two groups based on age (< 65 years and $\geq 65$ years) for statistical analyses of differences. Old age is typically defined as over 65 years based on old UK retirement standards. All continuous data were compiled as mean \pm standard deviation; categorical variables are reported as a percentage. We analysed quantitative variables using the student t-test and the Mann-Whitney U test (depending on whether data followed a normal distribution or not), while we used the Chi-squared test for categorical variables. To measure association, we used the odds ratio (OR) or adjusted OR (ORa) and expressed results with 95\% confidence intervals (CI). Moreover, we performed multiple logistic regression analyses (simultaneous regression) with age over 65 as an independent variable. Associations showing $p$ values of less than 0.05 were re-run in multivariable analyses. We compiled and analysed all data using SPSS software for Windows 22.0 (IBM Inc., New York).

The study was approved by the ethics committee for epidemiologic research at Hospital Universitario Sant Joan d'Alacant (2016/011). Due to the retrospective nature of the study, the need for informed consent was waived.

\section{Results}

Of the 102 patients with PLA, we excluded 4 due to age (paediatric cases in patients under 14). Mean age was 64.5 years $( \pm 15.4$; range 19 to 100$)$. Forty patients were younger than 65 , and 58 were aged 65 or older. Mean age in the younger group was 49.1 years $( \pm 10.0)$, compared to 79.1 years $( \pm 7.3)$ in the older group.

Table 1 shows the clinical and epidemiological characteristics of patients with PLA. Presence of fever, abdominal pain and jaundice, and history of cancer and colitis, were similar between groups. However, there were significant differences in the following variables 
Table 1 Main epidemiological and clinical characteristics of patients aged $<65$ years and $\geq 65$ years with liver abscess

\begin{tabular}{|c|c|c|c|c|c|c|c|c|}
\hline \multirow[t]{2}{*}{ Variables } & \multicolumn{2}{|c|}{ Total } & \multicolumn{2}{|c|}{ Aged $<65$ years } & \multicolumn{2}{|c|}{ Aged $\geq 65$ years } & \multirow[t]{2}{*}{ Odds ratio $(95 \% \mathrm{Cl})$} & \multirow[t]{2}{*}{$p$-value } \\
\hline & $\mathrm{N}$ & $\%$ & $\mathrm{~N}$ & $\%$ & $\mathrm{~N}$ & $\%$ & & \\
\hline \multicolumn{9}{|l|}{ Sex } \\
\hline Male & 61 & 82.2 & 36 & 90 & 25 & 43.1 & 1 & \\
\hline Female & 37 & 37.8 & 4 & 10 & 33 & 56.9 & $11.9(3.7,37.7)$ & $<0.001$ \\
\hline \multicolumn{9}{|l|}{ Clinical characteristics } \\
\hline Fever & 69 & 70.4 & 31 & 77.5 & 38 & 65.5 & $0.6(0.2,1.4)$ & 0.2 \\
\hline Abdominal pain & 37 & 37.9 & 26 & 65.0 & 35 & 60.3 & $0.8(0.4,1.9)$ & 0.6 \\
\hline Jaundice & 27 & 72.4 & 10 & 25.0 & 17 & 29.3 & $1.2(0.5,3.1)$ & 0.6 \\
\hline Sepsis & 18 & 18.4 & 3 & 7.5 & 15 & 25.9 & $4.3(1.2,16)$ & 0.02 \\
\hline \multicolumn{9}{|l|}{ Underlying condition } \\
\hline Cholelithiasis & 28 & 28.6 & 5 & 12.5 & 23 & 39.7 & $4.6(1.6,13.5)$ & 0.003 \\
\hline Chronic liver disease $^{a}$ & 15 & 15.3 & 11 & 27.5 & 4 & 6.9 & $0.2(0.06,0.7)$ & 0.005 \\
\hline Neoplasm ${ }^{c}$ & 13 & 13.3 & 3 & 7.5 & 10 & 17.2 & $2.6(0.7,10.0)$ & 0.2 \\
\hline Transplant recipient ${ }^{\text {b }}$ & 5 & 5.1 & 5 & 12.5 & 0 & 0 & N.A & 0.01 \\
\hline Inflammatory bowel disease & 5 & 5.1 & 4 & 10.0 & 1 & 1.7 & $0.2(0.01,1.5)$ & 0.2 \\
\hline \multicolumn{9}{|l|}{ Origin } \\
\hline Biliary & 43 & 43.9 & 9 & 22.5 & 34 & 58.6 & $4.9(2.0,12.1)$ & $<0.001$ \\
\hline Cryptogenic & 40 & 40.8 & 27 & 67.5 & 13 & 22.4 & $0.1(0.05,0.3)$ & $<0.001$ \\
\hline Contiguous & 6 & 6.1 & 2 & 5.0 & 4 & 6.9 & $1.4(0.2,8.0)$ & 0.7 \\
\hline Traumatic & 5 & 5.1 & 2 & 5.0 & 3 & 5.2 & $1.0(0.2,6.5)$ & 1 \\
\hline Portal & 3 & 3.1 & 0 & 0 & 3 & 5.2 & NA & 0.3 \\
\hline Arterial & 1 & 1.0 & 0 & 0 & 1 & 1.7 & NA & 1 \\
\hline
\end{tabular}

Cl confidence intervals, NA not applicable

a Chronic hepatopathy: alcoholic hepathopathy $(n=7)$, hepatitis $C$ virus $(n=4)$; hepatic steatosis $(n=3)$; and cirrohosis $(n=1)$

${ }^{\mathrm{b}}$ Transplant recipient*: 3 liver and 2 kidney

' Type of neoplasm: hepatocarcinoma $(n=4)$, adenocarcinoma of pancreas $(n=3)$, neoplasms of kidney $(n=2)$, cholangiocarcinoma $(n=1)$, hepatic metastasis $(n=1)$, adenocarcinoma of colon $(n=1)$, adenocarcinoma of breast $(n=1)$

in the older group compared to the younger one: female sex (OR 11.9; 95\% CI 3.7, 37.7); presence of sepsis (OR 4.3; 95\% CI 1.2, 16.0), history of cholelithiasis (OR 4.6; 95\% CI 1.6, 13.5), and absence of chronic liver disease (OR 0.2; 95\% CI 0.06, 0.7). In the older group, biliary origin was more common (OR 4.9; 95\% CI 2.0, 12.1) while cryptogenic origin was less so (OR 0.1, 95\% CI 0.05, 0.3).

The most frequent combination of imaging techniques used was abdominal ultrasound plus CT scan (48\%), followed by ultrasound plus CT plus MRI (18\%). Table 2 shows the comparison of techniques used in both groups. Mean PLA diameter in the older group was smaller $(4.2 \pm 3.0 \mathrm{~cm}$ vs. $5.6 \pm 3.6 \mathrm{~cm} ; p=0.04)$.

Table 3 compares laboratory data between groups. There were no significant differences in leukocyte counts, haemoglobin, alkaline phosphatase, total bilirubin or CRP. In contrast, there was a difference in GGT levels, which were higher in the older group.

The main microbiological diagnostic procedures were cultures of PLA tissue samples and blood cultures, which were both performed in $42.9 \%$ of the cases, followed by blood culture alone. Cultures were positive in $67.7 \%$ of the PLA tissue samples and $33.9 \%$ of the blood cultures. The main microorganism isolated as the cause of the PLA was E. coli (16.3\%), followed by Streptococcus anginosus group (13.3\%) (Table 4). E. coli was significantly more frequent in the older group (OR 6.0; 95\% CI 1.3, 28.4). Four gram-negative bacteria were identified as producers of beta-lactamases (two E. coli and two $K$. pneumonia): two in the older group (3.4\%) and two in the younger group (5.0\%).

Most patients received antibiotics plus percutaneous drainage $(61.2 \%)$ followed by antibiotic alone (31.6\%) and antibiotic plus surgical drainage (7.1\%); there was no significant difference between groups (Table 5). The main antibiotics used were penicillin/beta lactamase inhibitors $(31.6 \%)$ followed by metronidazole $(26.5 \%)$ and carbapenems (23.5\%); there was no significant difference between groups.

Table 6 describes the treatment used according to PLA size. Small PLAs were treated mainly with antibiotic alone 
Table 2 Imaging procedures of patients aged $<65$ years and $\geq 65$ years with liver abscess

\begin{tabular}{|c|c|c|c|c|c|c|c|c|}
\hline & \multicolumn{2}{|l|}{ Total } & \multicolumn{2}{|c|}{ Aged $<65$ years } & \multicolumn{2}{|c|}{ Aged $\geq 65$ years } & \multirow[t]{2}{*}{ Odds ratio (Cl 95\%) } & \multirow[t]{2}{*}{$p$-value } \\
\hline & $\mathrm{N}$ & $\%$ & $\mathrm{~N}$ & $\%$ & $\mathrm{~N}$ & $\%$ & & \\
\hline \multicolumn{9}{|c|}{ Diagnostic imaging procedure } \\
\hline $\mathrm{CT}$ scan & 83 & 84.7 & 38 & 95.0 & 45 & 77.6 & $0.2(0.04,0.8)$ & 0.02 \\
\hline Ultrasound & 80 & 81.6 & 30 & 75.0 & 50 & 86.2 & $2.1(0.7,5.8)$ & 0.2 \\
\hline MRI & 29 & 29.6 & 14 & 35.0 & 15 & 25.9 & $0.6(0.3,1.6)$ & 0.3 \\
\hline \multicolumn{9}{|l|}{ Single or multiple } \\
\hline Single & 54 & 55.1 & 34 & 58.6 & 20 & 50.0 & 1 & 0.4 \\
\hline Multiple & 44 & 44.9 & 20 & 45.5 & 24 & 41.4 & $0.7(0.3,1.6)$ & \\
\hline \multicolumn{9}{|l|}{ Size category } \\
\hline$<4 \mathrm{~cm}$ & 46 & 46.9 & 15 & 37.5 & 31 & 53.4 & $1.9(0.8,4.3)$ & $<0.15$ \\
\hline $4-9.9 \mathrm{~cm}$ & 42 & 42.9 & 20 & 50.0 & 22 & 37.9 & $0.6(0.7,1.4)$ & 0.235 \\
\hline \multirow[t]{2}{*}{$\geq 10 \mathrm{~cm}$} & 10 & 10.2 & 5 & 12.5 & 5 & 8.6 & $0.6(0.2,2.4)$ & 0.736 \\
\hline & mean & SD & mean & SD & mean & SD & & \\
\hline Side diameter (cm) & 4.8 & 3.3 & 5.6 & 3.6 & 4.2 & 3.0 & $0.9(0.8,0.99)$ & 0.04 \\
\hline \multicolumn{9}{|l|}{ Other imaging findings } \\
\hline Gallstones & 28 & 28.6 & 5 & 12.5 & 23 & 39.7 & $4.6(1.6,13.5)$ & 0.003 \\
\hline Gas formation & 6 & 6.1 & 2 & 5.0 & 4 & 6.9 & $1.4(0.2,8.0)$ & 0.7 \\
\hline Hepatocarcinoma & 4 & 4.1 & 1 & 2.5 & 3 & 5.2 & $3.2(0.5,6.0)$ & 0.9 \\
\hline Neoplasm of pancreas & 3 & 3.1 & 0 & 0 & 3 & 3.1 & NA & 1 \\
\hline Neoplasm of kidney & 2 & 2.0 & 0 & 0 & 2 & 3.2 & NA & 1 \\
\hline Cholangiocarcinoma & 1 & 1.0 & 0 & 0 & 1 & 1.7 & NA & 1 \\
\hline Hepatic metastasis & 1 & 1.0 & 1 & 2.5 & 0 & 0 & NA & 1 \\
\hline
\end{tabular}

Cl confidence intervals, SD standard deviation

$C T$ scan computerised tomography scan, MRI magnetic resonance imaging

$(p<0.001)$, while both large PLAs were treated with antibiotic plus percutaneous aspiration $(p<0.001)$. These seven patients who were treated with surgical drainage received it due to: cholecystitis and biliary complication $(n=4)$, neoplasm $(n=2)$ and peritonitis with continuous fever $(n=1)$.

Table 5 compares the adverse events encountered in the $55.1 \%$ of patients who experienced them $(25.5 \%$ of which were severe). The incidence of all types of complications and severe complication was higher in the older group (OR 2.3; 95\% CI 1.04, 5.4 and OR: 3.7; 95\% CI 1.2, 10.8 , respectively) compared to the younger one. The most frequent complications were pleural effusion (14.3\%) and septic shock (14.3\%), the latter of which was more common in the $\geq 65$ group (OR 4.9; $95 \%$ CI: 1.04 , 23.0). Mortality was $8.2 \%$ overall, although all deaths occurred in the older group $(13.8 \%)(p=0.02)$. On the other hand, the length of hospital stay was similar between groups.

Finally, Table 7 shows the results of the multivariable analysis in patients aged $\geq 65$ years with PLA. Significant associations were found with female sex (ORa 9.0; 95\% CI 1.4, 56.1), non-cryptogenic origin (ORa 14.5; 95\% CI 1.6, 129.0), absence of chronic liver disease

Table 3 Laboratory data of patients aged $<65$ years and $\geq 65$ years with liver abscess

\begin{tabular}{|c|c|c|c|c|c|c|c|c|}
\hline \multirow[t]{2}{*}{ Variables } & \multirow[t]{2}{*}{ Missing values } & \multicolumn{2}{|l|}{ Total } & \multicolumn{2}{|c|}{ Aged $<65$ years } & \multicolumn{2}{|c|}{ Aged $\geq 65$ years } & \multirow[t]{2}{*}{$p$-value } \\
\hline & & Mean & SD & Mean & SD & Mean & SD & \\
\hline Leukocyte $\geq 12.0 \times 10^{9} / \mathrm{L}$ & $0: 4$ & 14.3 & 7.0 & 13.7 & 4.9 & 14.8 & 8.2 & 0.4 \\
\hline Haemoglobin (g/L) & $1: 4$ & $12-0$ & 2.2 & 12.0 & 2.1 & 12.3 & 2.3 & 0.1 \\
\hline Alkaline phosphatase (mg/dL) & $8: 12$ & 208 & 160 & 179 & 149 & 228 & 168 & 0.3 \\
\hline Gamma glutamyl transferase (IU/dL), & $18: 10$ & 338 & 405 & 219 & 189 & 437 & 503 & 0.04 \\
\hline Total bilirubin (mg/dL), & $1: 8$ & 1.7 & 1.7 & 1.8 & 1.9 & 1.6 & 1.6 & 0.7 \\
\hline C reactive protein (mg/dL) & $5: 9$ & 18.1 & 11.8 & 19.7 & 12.7 & 17.0 & 10.9 & 0.3 \\
\hline
\end{tabular}


Table 4 Microbial diagnostic procedure and microbiological diagnosis of patients aged $<65$ years and $\geq 65$ years with liver abscess

\begin{tabular}{|c|c|c|c|c|c|c|c|c|}
\hline \multirow[t]{2}{*}{ Variables } & \multicolumn{2}{|l|}{ Total } & \multicolumn{2}{|c|}{ Aged $<65$ years } & \multicolumn{2}{|c|}{ Aged $\geq 65$ years } & \multirow[t]{2}{*}{ Odds ratio (Cl 95\%) } & \multirow[t]{2}{*}{$p$-value } \\
\hline & $\mathrm{N}$ & $\%$ & $\mathrm{~N}$ & $\%$ & $\mathrm{~N}$ & $\%$ & & \\
\hline \multicolumn{9}{|l|}{ Microbial diagnostic procedure } \\
\hline No culture & 19 & 19.4 & 5 & 12.5 & 14 & 24.1 & $2.2(0.7,6.8)$ & 0.1 \\
\hline Culture of abscess & 20 & 20.4 & 7 & 17.5 & 13 & 22.4 & $1.3(0.5,3.8)$ & 0.5 \\
\hline Blood culture & 17 & 17.3 & 6 & 15.0 & 11 & 19.0 & $1.3(0.4,3.9)$ & 0.6 \\
\hline Culture of abscess + blood culture & 42 & 42.9 & 22 & 55.0 & 20 & 34.5 & $0.4(0.2,0.98)$ & 0.04 \\
\hline \multicolumn{9}{|l|}{ Results } \\
\hline Positive culture of abscess & $44 / 65$ & 67.7 & $21 / 30$ & 70 & $23 / 35$ & 65.7 & $0.8(0.3,2.3)$ & 0.7 \\
\hline Positive blood culture & $20 / 59$ & 33.9 & $9 / 28$ & 32.1 & $11 / 31$ & 35.5 & $1.1(0.3,3.4)$ & 0.8 \\
\hline \multicolumn{9}{|l|}{ Microorganisms } \\
\hline Escherichia coli & 16 & 16.3 & 2 & 5.0 & 14 & 24.1 & $6.0(1.3,28.4)$ & 0.01 \\
\hline Streptococcus anginosus group ${ }^{a}$ & 13 & 13.3 & 7 & 17.5 & 6 & 10.3 & $0.5(0.7,1.7)$ & 0.2 \\
\hline Klebsiella spp. ${ }^{b}$ & 11 & 11.2 & 7 & 17.5 & 4 & 6.9 & $0.3(0.09,1.2)$ & 0.1 \\
\hline Enterococcus spp. & 5 & 5.1 & 1 & 2.5 & 4 & 6.9 & $2.9(0.3,26.8)$ & 0.3 \\
\hline Streptococcus mitis & 4 & 4.1 & 3 & 7.5 & 1 & 1.7 & $0.2(0.02,2.1)$ & 0.2 \\
\hline Porphyromonas spp. & 3 & 3.1 & 1 & 2.5 & 2 & 3.4 & $1.4(0.1,15.9)$ & 0.8 \\
\hline Pseudomonas aeruginosa & 3 & 3.1 & 2 & 5.0 & 1 & 1.7 & $0.3(0.03,3.8)$ & 0.4 \\
\hline Citrobacter spp. & 2 & 2.0 & 0 & 0 & 2 & 3.4 & NA & 0.2 \\
\hline Enterobacter cloacae & 1 & 1.0 & 0 & 0 & 1 & 1.7 & NA & 1 \\
\hline Fusobacterium spp. & 1 & 1.0 & 1 & 2.5 & 1 & 1.7 & NA & 1 \\
\hline Eikenella corrodens & 1 & 1.0 & 0 & 0 & 1 & 1.7 & NA & 1 \\
\hline Candida albicans & 1 & 1.0 & 0 & 0 & 1 & 1.7 & NA & 1 \\
\hline Magnusiomyces capitatus & 1 & 1.0 & 0 & 0 & 1 & 1.7 & NA & 1 \\
\hline Total patients with positive cultures & 54 & 55.1 & 23 & 57.5 & 31 & 53.4 & $0.8(0.4,1.9)$ & 0.7 \\
\hline Polymicrobial infections & 7 & 7.1 & 3 & 7.5 & 4 & 6.9 & $0.9(0.2,4.3)$ & 0.9 \\
\hline
\end{tabular}

Cl confidence intervals, NA not applicable

${ }^{a}$ Streptococcus anginosus group include S. constellatus, S. milleri, S. intermedius and S. anginosus

${ }^{\mathrm{b}}$ Klebsiella spp. includes: K. pneumoniae and K. oxytoca

(ORa 14.0; 95\% CI 1.3, 155.1), and E. coli infection (ORa 7.7; 95\% CI 1.03, 58.0).

In total, eight patients $(8.2 \%)$ died due to PLA. The leukocyte counts in the patients who died were significantly higher than in those whose clinical evolution was favourable $\left(20.1 \pm 11.1 \times 10^{6} / \mathrm{L}\right.$ vs. $\left.13.9 \pm 6.6 \times 10^{6} / \mathrm{L}\right)$ $(p=0.01)$. All of the patients who died experienced sepsis, compared to $11.1 \%$ of those who survived, and $87.8 \%$ presented with septic shock, compared to $7.8 \%$ of the survivors $(p<0.001)$. The rest of the variables explored were not related to mortality. In the multivariable analysis, no association was observed with mortality.

\section{Discussion}

Although overall incidence of PLA remained stable throughout the study period, its distribution between age groups showed a clear variation. In the earliest years, the most affected age groups corresponded to people aged 30-49 years, while more recent periods show a higher incidence among patients aged 50-69 [14-17]. This trend can be attributed to the decreasing incidence of abscesses related to acute appendicitis as an aetiopathogenic factor (more common among younger patients) and the greater incidence of neoplasms and complex biliary diseases observed at more advanced ages $[1,2,14-17]$.

In this study, we describe our experience in our area within the context of existing literature. We have found some significant differences in the $<65$ and $\geq 65$ age groups. There were more women in the older age group, and older patients also more commonly had a history of biliary pathology and no chronic liver disease, with a greater likelihood of $E$. coli infection.

Our results are in consonance with other published studies. Older patients with PLA tend to present more anomalies in the biliary tract $[7,8,18,19,20]$, while younger patients are more often male and present more 
Table 5 Treatment, complications and outcomes of patients aged $<65$ years and $\geq 65$ years with liver abscess

\begin{tabular}{|c|c|c|c|c|c|c|c|c|}
\hline & \multicolumn{2}{|l|}{ Total } & \multicolumn{2}{|c|}{ Aged $<65$ years } & \multicolumn{2}{|c|}{ Aged $\geq 65$ years } & \multirow[t]{2}{*}{ Odds ratio (Cl 95\%) } & \multirow[t]{2}{*}{$p$-value } \\
\hline & $\mathrm{N}$ & $\%$ & N & $\%$ & $\mathrm{~N}$ & $\%$ & & \\
\hline \multicolumn{9}{|l|}{ Treatment } \\
\hline Antibiotic alone & 31 & 31.6 & 11 & 27.5 & 20 & 34.5 & $1.4(0.6,3.3)$ & 0.5 \\
\hline Antibiotic + percutaneous aspiration & 60 & 61.2 & 28 & 70 & 32 & 55.2 & $0.5(0.2,1.2)$ & 0.1 \\
\hline Antibiotic + surgical drainage \pm percutaneous aspiration & 7 & 7.1 & 1 & 2.5 & 6 & 10.3 & $4.5(0.5,38.9)$ & 0.1 \\
\hline \multicolumn{9}{|l|}{ Antibiotics used ${ }^{a}$} \\
\hline Penicillins/beta-lactamase inhibitors & 31 & 31.6 & 16 & 40 & 15 & 25.9 & $0.5(0.2,1,2)$ & 0.1 \\
\hline Metronidazole & 25 & 26.5 & 14 & 35.0 & 12 & 20.7 & $4.5(0.2,1.2)$ & 0.1 \\
\hline Carbapenems & 23 & 23.5 & 9 & 22.5 & 14 & 24.1 & $1,1(0.4,2.8)$ & 0.8 \\
\hline Fluoroquinolones & 20 & 20.4 & 7 & 17.5 & 13 & 22.4 & $1.4(0.5,3.8)$ & 0.5 \\
\hline Cephalosporins & 15 & 25.5 & 8 & 20.0 & 17 & 29,3 & $1.7(0.6,4.3)$ & 0.3 \\
\hline \multicolumn{9}{|l|}{ Complications } \\
\hline Any complication & 54 & 55.1 & 17 & 42.5 & 37 & 68.5 & $2.3(1.04,5.4)$ & 0.04 \\
\hline Severe complications & 25 & 25.5 & 5 & 12.5 & 20 & 34.5 & $3.7(1.2,10.8)$ & 0.01 \\
\hline \multicolumn{9}{|l|}{ Type of complications } \\
\hline Septic shock & 14 & 14.3 & 2 & 5.0 & 12 & 20.7 & $4.9(1.04,23)$ & 0.03 \\
\hline Pleural effusion & 14 & 14.3 & 6 & 15.0 & 8 & 13.8 & $0.9(0.3,2.8)$ & 0.9 \\
\hline Acute renal failure & 8 & 8.2 & 1 & 2.5 & 7 & 12.1 & $5.3(0.6,45.3)$ & 0.09 \\
\hline Cardiac complications & 8 & 8.2 & 1 & 2.5 & 7 & 12.1 & $5.3(0.6,45)$ & 0.09 \\
\hline Thrombosis & 6 & 6.1 & 4 & 10.0 & 2 & 2.0 & $0.3(0.05,1.8)$ & 0.2 \\
\hline Biliary-pancreatic complication & 5 & 5.1 & 2 & 5.0 & 3 & 5.1 & $2.1(0.5,11)$ & 0.8 \\
\hline Infectious complications & 4 & 4.1 & 1 & 2.5 & 3 & 5.2 & $2.1(0.2,21,2)$ & 0.5 \\
\hline Peritonitis & 1 & 1.0 & 0 & 0 & 1 & 1.7 & NA & 1 \\
\hline Abdominal haematoma & 1 & 1.0 & 0 & 0 & 1 & 1.7 & NA & 1 \\
\hline \multicolumn{9}{|l|}{ Outcome } \\
\hline \multirow[t]{2}{*}{ Death } & 8 & 8.2 & 0 & 0 & 8 & 13.8 & NA & 0.02 \\
\hline & mean & SD & mean & SD & mean & SD & & \\
\hline Admission days & 19.3 & 12.8 & 19.5 & 11.9 & 18.9 & 13.5 & NA & 0.728 \\
\hline
\end{tabular}

$\mathrm{Cl}$ confidence intervals, NA not applicable, $S D$ standard deviation

aOther antibiotics: amynoglucosides $(n=4)$, glycopetide $(n=3)$, clindamicin $(n=1)$

Table 6 Treatment and mortality according to size of liver abscess

\begin{tabular}{|c|c|c|c|c|c|c|c|}
\hline & \multicolumn{7}{|c|}{ Size category } \\
\hline & \multicolumn{2}{|c|}{$\begin{array}{l}<4 \mathrm{~cm} \\
(n=46)\end{array}$} & \multicolumn{2}{|c|}{$\begin{array}{l}4-9.9 \mathrm{~cm} \\
(n=42)\end{array}$} & \multicolumn{2}{|c|}{$\begin{array}{l}\geq 10 \mathrm{~cm} \\
(n=10)\end{array}$} & \multirow[t]{2}{*}{$p$-value } \\
\hline & $\bar{N}$ & $\%$ & $\bar{N}$ & $\%$ & $\bar{N}$ & $\%$ & \\
\hline \multicolumn{8}{|l|}{ Treatment } \\
\hline Antibiotic alone & 24 & 52.2 & 7 & 16.7 & 0 & 0 & $<0.001$ \\
\hline Antibiotic + percutaneous aspiration & 19 & 41.3 & 32 & 76.2 & 9 & 90 & 0.001 \\
\hline Antibiotic + surgical drainage $\mathrm{e}^{\mathrm{a}}$ & 3 & 6.5 & 3 & 7.1 & 1 & 10 & 0.9 \\
\hline Mortality & 4 & 8.7 & 4 & 9.5 & 0 & 0 & 0.9 \\
\hline
\end{tabular}

${ }_{ \pm} \pm$percutaneous aspiration 
Table 7 Multivariable analysis in patients $\geq 65$ years with liver abscess

\begin{tabular}{lll}
\hline & Odds ratio adjusted (Cl 95\%) & $p$-value \\
\hline Sex, female & $9.0(1.4,56.0)$ & 0.02 \\
Source of origin: non-cryptogenic & $14.5(1.6,129.0)$ & 0.02 \\
Underlying condition: not chronic liver disease & $14(1.3,15.05)$ & 0.03 \\
Infection due to E. coli & $7.7(1.03,58.0)$ & 0.05 \\
Side diameter & $0.8(0.08,1.9)$ & 0.1 \\
Source of origin: biliary & $5.1(0.5,58.3)$ & 0.2 \\
Any complications & $2.6(0.5,12.5)$ & 0.2 \\
Septic shock & $24(0.2,3568)$ & 0.2 \\
Underlying condition: cholelithiasis & $2.6(0.4,14.1)$ & 0.3 \\
Clinical presentation, sepsis & $0.2(0.01,3.3)$ & 0.3 \\
Specific severe complications & $1.3(0.08,20.1)$ & 0.8 \\
Underlying condition: transplant recipient & NA & 0.9 \\
Death & NA & 0.9 \\
\hline Cl confidence
\end{tabular}

$\mathrm{Cl}$ confidence intervals

commonly with previous liver disease (especially related to alcohol) and cryptogenic PLA [19].

With regard to epidemiologic characteristics, our findings in elderly patients were also consistent with the literature, with a predominance of women in the older group and men in the younger group $[8,21,22]$. This may be due to the different life expectancies between sexes as well as the greater prevalence of chronic liver disease among younger patients in our study. In contrast, the presence of cholelithiasis was more pronounced in the older group.

In the univariate analysis only, neoplasms (particularly hepatocarcinoma) were significantly more prevalent in the older group, whereas inflammatory bowel disease was significantly less prevalent in the younger group $(p>0.05)$. In other studies, older patients with PLA tend to present more underlying malignant diseases $[7,8,19,20]$. Moreover, transplant recipients were only in the younger group, as advanced age is an exclusion criterion for liver transplant waitlists.

The advantage of CT scans over ultrasounds resides in the detection of small ( $\leq 0.05 \mathrm{~cm}$ diameter) deposits and the possibility of correctly exploring the superior subsegment of the posterior segment of the liver [23-25]. Moreover, the CT can provide information about the existence of PLA-associated disease outside the liver, such as appendicitis, diverticulitis, cancer, etc. In light of these advantages, many authors consider the $\mathrm{CT}$ to be the best initial diagnostic procedure in patients with suspicion of PLA [23].

Recently, MRI has been incorporated into the diagnostic toolkit for the study of abdominal pathologies, rivalling the $\mathrm{CT}$ in the detection of PLA. A theoretical advantage of the MRI over the $\mathrm{CT}$ is that it provides better information about the hepatic venous anatomy; however, the relationship between an abscess and the hepatic veins can be seen by ultrasound [25]. With regard to the use of diagnostic imaging techniques, we did not find statistically significant differences between groups. The ultrasound and CT are used widely, to a much greater extent than the MRI. In any case, age does not appear to be a significant factor for physicians when deciding which radiologic method to use. Consistent with other studies, PLA alone was the most frequent form of presentation in both of our groups. On the other hand, the maximum diameter was greater (and showed statistical significance) in the younger group.

With regard to the laboratory findings at the time of the consult, we did not observe significant differences in the variables collected, including bilirubin or leukocyte values. These data are consistent with those reported elsewhere $[1,4,5]$. We only found a significant difference in the higher value of GGT among the older group, probably due to the greater biliary aetiology of liver abscesses in this study.

The main microbiological technique was the culture of PLA tissue, which was usually accompanied by blood culture. We did not observe significant differences between groups, either in the technique used or the positivity found. Traditional series show $S$. aureus to be the principal germ isolated in hepatic cultures, but E. coli is also a common cause of PLA [25]. K. pneumoniae PLA have been widely described, particularly in southeast Asian countries [26, 27]. In in our series, K. pneumoniae was not the most common microorganism, but rather $E$. coli followed by the S. anginosus group; K. pneumoniae ranked third. The differences observed in our study may be because we did not perform enough blood cultures or obtain sufficient pus for cultures, or possibly because antibiotics were administered before cultures were 
obtained. In this case, cultures may not test positive the first time, and isolating the microorganism may require multiple attempts [28]. In a recent comparative study of PLA in 264 patients with $K$. pneumonia and 24 patients with $E$. coli, the latter bacterium affected older patients and was more commonly associated with hyperbilirubinemia, increased GGT and gallstones [13]. Likewise, in our study $E$. coli and gallstones were significantly more common in patients over 65 .

Today, surgical treatment of PLA has been relegated in favour of the current frontline treatments of antibiotics and aspiration/drainage of the PLA [29, 30, 31]. Moreover, laparoscopic drainage of PLA has also recently been developed as an option for surgical drainage of liver abscess [32]. Our series also reflected this situation; the first treatment was antibiotics and percutaneous aspiration/drainage of PLA, followed by antibiotic alone. Few patients received antibiotics plus surgical treatment, and only one underwent laparoscopic drainage. There were no differences in treatment of PLA between age groups, nor was type of treatment associated with mortality. This observation points to both the appropriateness of the treatment and to the fact that therapeutic efforts are not rationed in older patients.

The use of antibiotics was variable in our study, as in this clinical practice, each attending physician decided the treatment, its duration and the time for switching from intravenous to oral administration. This is a limitation of all retrospective studies, including ours. In intraabdominal infections, it is important remember to appropriately prescribe antibiotics - and to limit the length of treatment - in order to avert antibiotic resistance [33]. Moreover in our study, the beginning of the antibiotic treatment was not recorded; however, when PLA (or other intra-abdominal infections) is suspected, quickly starting a course of antibiotics reduces mortality [34].

The appearance of complications, especially septic shock, was more common in patients aged $\geq 65$ years. This finding can be explained by the elevated comorbidity in older patients (neoplasm, diabetes mellitus, etc.) [35]. In our study the mortality was $8.2 \%$ overall, although all deaths occurred in patients aged $\geq 65$ years (about $14 \%$ of cases in this age group). The mortality in these cases was not really due to age, but rather comorbidities and PLA complications in patients with comorbidities; these factors were more important than age alone. Recently, Martínez-Cecilia et al. reported that octogenarians have comparable outcomes to younger people in colorectal liver metastases when treated with laparoscopic liver resection [36]. Thus, comorbidity and complications are more important prognostic factors than age.

Our study has the inherent limitations of all retrospective studies, particularly the risk of information bias, as it was not always possible to extract all necessary information about the cases.

\section{Conclusions}

In conclusion, in our study, there were more women in the $\geq 65$ age group, and older patients also more commonly had a history of biliary pathology and no chronic liver disease, with a greater likelihood of $E$. coli infection. Death and complications, especially sepsis, were more frequent in older patients, justifying increased efforts for early detection and prompt treatment in this group.

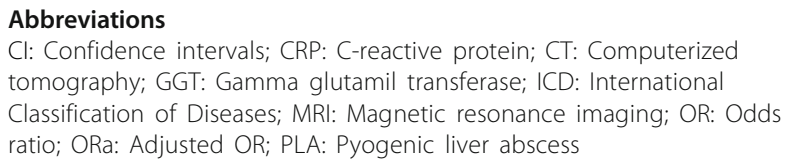

Acknowledgements

We thank Meggan Harris at Rosetta Manuscripts for her edition of this paper.

\section{Funding}

This research received no specific grant from any funding agency in the public, commercial or non-profit sectors.

\section{Availability of data and materials}

The datasets used and/or analysed during the current study available from the corresponding author on reasonable request.

\section{Financial competing interests}

There are any non-financial competing interests to declare in relation to this manuscript.

\section{Authors' contributions}

JP and JMR were responsible for the study design; JP, JMR, PR, and SC were responsible for data collection; JP and JMR did statistical analysis, JP, JMR, PR, $P B, S R, S C, J M P$, and GGA participated in the analysis and interpretation of the data. All authors drafted, prepared, read and approved the final version of the manuscript

\section{Ethics approval and consent to participate}

The study protocol was approved by the ethics committee for epidemiologic research at Hospital Universitario Sant Joan d'Alacant. Due to the retrospective nature of the study, the need for informed consent was waived.

\section{Consent for publication}

Not applicable.

\section{Competing interests}

The authors declare that they have no competing interests.

\section{Publisher's Note}

Springer Nature remains neutral with regard to jurisdictional claims in published maps and institutional affiliations.

\section{Author details}

'Deparment of Internal Medicine, Hospital Universitario Sant Joan d'Alacant, Sant Joan d'Alacant, Alicante, Spain. ²Department of Clinical Medicine, Universidad Miguel Hernández de Elche, Campus of Sant Joan d'Alacant, Sant Joan d'Alacant, Alicante, Spain. ${ }^{3}$ Gastroenterology and Hepatology Service, Hospital General Universitario de Alicante, Alicante, Alicante, Spain. ${ }^{4}$ Unit of Infectious Diseases, Department of Internal Medicine, Hospital General Universitario de Alicante, Alicante, Alicante, Spain. ${ }^{5}$ Family Medicine Department, Campello Health Centre, El Campello, Alicante, Spain.

${ }^{6}$ Department of History of Science and Documentation, University of 
Valencia, Valencia, Valencia, Spain. ${ }^{7}$ Department of Internal Medicine, Hospital General Universitario de Alicante Alicante, Alicante, Alicante, Spain.

\section{Received: 28 January 2017 Accepted: 11 July 2017 Published online: 21 July 2017}

\section{References}

1. Mohsen AH, Green ST, Read RC, McKendrick MW. Liver abscess in adults: ten years experience in a UK Centre. QJM. 2002;95:797-802.

2. Kaplan GG, Gregson DB, Laupland KB. Population-based study of the epidemiology of and the risk factors for pyogenic liver abscess. Clin Gastroenterol Hepatol. 2004;2:1032-8.

3. Tsai FC, Huang YT, Chang LY, Wang JT. Pyogenic liver abscess as endemic disease, Taiwan. Emerg Infect Dis. 2008;14:1592-600.

4. Lo JZ, Leow JJ, Ng PL, Lee HQ, Mohd Noor NA, Low JK, Junnarkar SP, Woon WW. Predictors of therapy failure in a series of 741 adult pyogenic liver abscesses. J Hepatobiliary Pancreat Sci. 2015;22:156-65.

5. Huang CJ, Pitt HA, Lipsett PA, Osterman FA Jr, Lillemoe KD, Cameron JL, et al. Pyogenic hepatic abscess. Changing trends over 42 years. Ann Surg. 1996:223:600-7.

6. Meddings L, Myers RP, Hubbard J, Shaheen AA, Laupland KB, Dixon E, et al. A population-based study of pyogenic liver abscesses in the United States: incidence, mortality, and temporal trends. Am J Gastroenterol. 2010;105:117-24.

7. Qu K, Liu C, Wang ZX. Pyogenic liver abscesses associated with nonmetastatic colorectal cancers: an increasing problem in eastern Asia. World J Gastroenterol. 2012;18:2948-295.

8. Rahimian J, Wilson T, Oram V, Holzman RS. Pyogenic liver abscess: recent trends in etiology and mortality. Clin Infect Dis. 2004;39:1654-9.

9. Ruiz-Hernández JJ, León-Mazorra M, Conde-Martel A, Marchena-Gómez J, Hemmersbach-Miller M, Betancor-León P. Pyogenic liver abscesses: mortality-related factors. Eur J Gastroenterol Hepatol. 2007;19:853-8.

10. Yaita K, Sameshima I, Takeyama H, Matsuyama S, Nagahara C, Hashiguchi R, et al. Liver abscess caused by multidrug-resistant Pseudomonas Aeruginosa treated with Colistin; a case report and review of the literature. Intern Med. 2013;52:1407-12.

11. Chen SC, Lee YT, Yen CH. Pyogenic liver abscess in the elderly: clinical features, outcomes and prognostic factors. Age Ageing. 2009;38:271-6.

12. Alvarez JA, González JJ, Baldonedo RF. Pyogenic liver abscesses:a comparison of older and younger patients. HPB (Oxford). 2001;3:201-6.

13. Shelat VG, Chia CL, Yeo CS, Qiao W, Woon W, Junnarkar SP. Pyogenic liver abscess: does Escherichia Coli cause more adverse outcomes than Klebsiella Pneumoniae? World J Surg. 2015;39:2535-42.

14. Hansen PS, Schonheyder HC. Pyogenic hepatic abscess. A 10-year population-based retrospective study. APMIS. 1998;106:396-402.

15. Barrio J, Cosme A, Ojeda E, Garmendia G, Castiella A, Bujanda L, et al. Abscesos hepáticos piógenos de origen bacteriano. Estudio de una serie de 45 casos. Rev Esp Enf Digest. 2000;92:232-5.

16. Mcdonald MI, Corey GR, Gallis HA, Durack DT. Single and multiple pyogenic liver abscesses. Natural history, diagnosis, and treatment, with emphasis on percutaneous rainage. Medicine. 1984;63:291-302.

17. Corredoira Sánchez JC, Casariego Vales E, Ibáñez Alonso MD, Rigueiro Veloso MT, Coira Nieto A, Alonso García P, et al. Absceso hepático piógeno: cambios en la etiología, diagnóstico y tratamiento a lo largo de 18 años. Rev Clin Esp. 1999:199:705-10.

18. Seeto RK. Rockey DC Pyogenic liver abscess. Changes in etiology, management, and outcome. Medicine (Baltimore). 1996;75:99-113.

19. Kao WY, Hwang CY, Chang YT, Su CW, Hou MC, Lin HC, et al. Cancer risk in patients with pyogenic liver abscess: a nationwide cohort study. Aliment Pharmacol Ther. 2012;36:467-76.

20. Lai HC, Lin CC, Cheng KS, Kao JT, Chou JW, Peng C, et al. Increased incidence of gastrointestinal cancers among patients with pyogenic liver abscess: a population-based cohort study. Gastroenterology. 2014;146:129-37.

21. Mavilia MG, Molina M, Wu GY. The evolving nature of hepatic abscess: a review. J Clin Transl Hepatol. 2016;4:158-68.

22. Lardière-Deguelte $\mathrm{S}$, Ragot E, Armoun K, Piardi T, Dokmak S, Bruno O, et al. Hepatic abscess: diagnosis and management. J Visc Surg. 2015;152:231-43.

23. Lin AC, Yeh DY, Hsu YH, Wu CC, Chang H, Jang TN, et al. Diagnosis of pyogenic liver abscess by abdominal ultrasonography in the emergency department. Emerg Med J. 2009:26:273-5.

24. Bonder A, Afdhal N. Evaluation of liver lesions. Clin Liver Dis. 2012;16:271-83.
25. Chemaly RF, Hall GS, Keys TF, Procop GW. Microbiology of liver abscesses and the predictive value of abscess gram stain and associated blood cultures. Diagn Microbiol Infect Dis. 2003:46:245-8.

26. Fazili T, Sharngoe C, Endy T, Kiska D, Javaid W, Polhemus M. Klebsiella Pneumoniae liver abscess: an emerging disease. Am J Med Sci. 2016; 351:297-304.

27. Siu LK, Yeh KM, Lin JC, Fung CP, Chang FY. Klebsiella Pneumoniae liver abscess: a new invasive syndrome. Lancet Infect Dis. 2012;12:881-7.

28. Shelat VG, Wang Q, Chia CL, Wang Z, Low JK, Woon WW. Patients with culture negative pyogenic liver abscess have the same outcomes compared to those with Klebsiella Pneumoniae pyogenic liver abscess. Hepatobiliary Pancreat Dis Int. 2016;15:504-11.

29. Ahmed S, Chia CL, Junnarkar SP, Woon W, Shelat VG. Percutaneous drainage for giant pyogenic liver abscess-is it safe and sufficient? Am J Surg. 2016;211:95-101.

30. Liao WI, Tsai SH, Yu CY, Huang GS, Lin YY, Hsu CW, et al. Pyogenic liver abscess treated by percutaneous catheter drainage: MDCT measurement for treatment outcome. Eur J Radiol. 2012;81:609-15.

31. Liu CH, Gervais DA, Hahn PF, Arellano RS, Uppot RN, Mueller PR, et al. Percutaneous hepatic abscess drainage: do multiple abscesses or multiloculated abscesses preclude drainage or affect outcome? J Vasc Interv Radiol. 2009:20:1059-65.

32. Wang W, Lee WJ, Wei PL, Chen TC, Huang MT. Laparoscopic drainage of pyogenic liver abscesses. Surg Today. 2004;34:323-5.

33. Sartelli M, Weber DG, Ruppé E, Bassetti M, Wright BJ, Ansaloni L, et al. Antimicrobials: a global alliance for optimizing their rational use in intraabdominal infections (AGORA). World J Emerg Surg. 2016;11:33.

34. Sartelli M, Abu-Zidan FM, Catena F, Griffiths EA, Di Saverio S, Coimbra R, et al. Global validation of the WSES sepsis severity score for patients with complicated intra-abdominal infections: a prospective multicentre study (WISS study). World J Emerg Surg. 2015;10:61.

35. Ramos JM, Sánchez-Martínez R, Nieto F, Sastre J, Valero B, Priego M, et al. Characteristics and outcome in nonagenarians admitted in general internal medicine and other specialties. Eur J Intern Med. 2013;24:740-4.

36. Martínez-Cecilia D, Cipriani F, Vishal S, Ratti F, Tranchart H, Barkhatov L. Laparoscopic versus open liver resection for colorectal metastases in elderly and octogenarian patients: a multicenter propensity score based analysis of short- and long-term outcomes. Ann Surg. 2017;265:1192-200.

\section{Submit your next manuscript to BioMed Central and we will help you at every step:}

- We accept pre-submission inquiries

- Our selector tool helps you to find the most relevant journal

- We provide round the clock customer support

- Convenient online submission

- Thorough peer review

- Inclusion in PubMed and all major indexing services

- Maximum visibility for your research

Submit your manuscript at www.biomedcentral.com/submit
) Biomed Central 